\title{
TUTORIA PRESENCIAL: MEDIAÇÃO, INTERAÇÃO E ATENDIMENTO AO ALUNO EAD
}

TAUBATÉ/SP MAIO/2018

\author{
Antonia Lucineire de Almeida - UNITAU - antonia@epts.com.br \\ Patrícia Ortiz Monteiro - UNITAU - patricia@epts.com.br
}

Tipo: Relato de Experiência Inovadora (EI)

Categoria: Métodos e Tecnologias

Setor Educacional: EDUCAÇÃO SUPERIOR

\begin{abstract}
RESUMO
Este trabalho visa apresentar um modelo de Tutoria Presencial como estruturação de atendimento aos alunos, na Universidade de Taubaté - UNITAU, situada na Região Metropolitana do Vale do Paraíba e Litoral Norte de São Paulo - RMVPLN. A Tutoria Presencial foi implantada pela instituição após observação da demanda de atendimento aos alunos, a fim de viabilizar o processo de comunicação e interação, por meio de várias ferramentas, além do Ambiente Virtual de Aprendizagem. A estruturação previu a realocação dos Docentes dos cursos em plantões presenciais, cujas atividades são esmiuçadas neste trabalho. A Tutoria Presencial tem como premissa realizar um atendimento personalizado aos alunos sobre assuntos acadêmicos, curriculares e pedagógicos, que são realizados nos plantões presenciais das áreas/cursos. Como aporte metodológico apresenta-se uma pesquisa descritiva e qualitativa. Sobre os resultados, com apenas três meses de implantação o setor já mostrou que os alunos buscam o atendimento para assuntos variados, a fim de obter resposta mais rápida. Observou-se também que o canal de comunicação mais utilizado é o WhatsApp. Como parte da função os Tutores registram os atendimentos num sistema acadêmico interno da instituição, fato que proporciona dados qualitativos relevantes para a $E A D$, para que sejam analisados e para que novas melhorias sejam implantadas para contribuir com a qualidade da educação oferecida
\end{abstract}

Palavras-chave: Tutoria Presencial; EAD; Atendimento ao Aluno; Interação; Comunicação.

AGRADECIMENTOS

O PRESENTE TRABALHO FAZ PARTE DAS PESQUISAS QUE SÃO DESENVOLVIDAS NO NÚCLEO DE ESTUDOS E PESQUISAS INTERDISCIPLINARES EM SABERES E PRÁTICAS EM EDUCAÇÃO A DISTÂNCIA DO NEAD DA UNIVERSIDADE DE TAUBATÉ. 


\section{1 - Introdução}

A Tutoria na Educação à Distância se configura como aporte pedagógico e acadêmico para os discentes. O papel desempenhado por este profissional se traduz na ponte entre as expectativas e necessidades do alunado, de um lado, e a organização e estruturação da instituição de outro lado.

Tem-se na EAD um modelo educacional tecnológico e interativo. É justamente nessa caracterização que se enfatiza a necessidade de um processo de mediação e interação que atende ao alunado, considerando seus diversos perfis e contextos os quais participam.

Nesse sentido e, a partir de observações no cotidiano da instituição constatou-se que os alunos anseiam por atendimento mais rápido e que atenda às variadas demandas do alunado. Identificou-se que os questionamentos e solicitações abordavam questões de ordem acadêmica, curricular e pedagógica.

Dessa forma e tendo em vista um processo de melhoria contínua a Instituição optou pela estruturação de Tutoria Presencial com plantões dos docentes dos cursos oferecidos. Essa experiência é relatada a seguir considerando os três primeiros meses de implantação, que já mostrou a relevância dessa estruturação no atendimento e contentamento dos alunos.

\section{1 - Objetivos}

Este estudo apresenta como objetivo geral:

- Apresentar a Tutoria Presencial como nova estruturação para atendimento personalizado aos alunos.

Os objetivos específicos são:

- Mostrar as funções desempenhadas e a organização dos plantões de Tutoria.

- Conhecer os resultados iniciais e preliminares da primeira etapa de implantação da Tutoria Presencial.

\section{2 - Desenvolvimento}


A Educação está sempre em transformação e nas últimas décadas parte dessa mudança é provocada pela Educação a Distância. É relevante a evolução da EAD no cenário educacional brasileiro e com essa o aprimoramento de tecnologias comunicacionais e informacionais, fato que mostra o sucesso de várias experiências nesta área (SILVA, 2013).

A aprendizagem é a premissa de um processo educacional mediado pela tecnologia que é a proposta base da EAD. Nesse contexto, Masetto (2000) destaca que a aprendizagem, o papel do aluno e do professor e a tecnologia permeiam a educação a distância e permite o desenvolvimento do ser humano.

Diante de um contexto de inovações tecnológicas pode-se destacar o avanço e as atualizações de uma das plataformas mais utilizadas na estruturação de cursos em EAD, o Moodle - Modular Object Oriented Dynamic Learning Environment, que hospeda um ambiente de fácil manuseio, que possui uma gama de ferramentas para sua organização (ALVES et al, 2009).

Neste ínterim, a plataforma educacional é uma parte importante da estruturação de cursos à distância. Essa plataforma pode inclusive ser customizada, conforme a necessidade de cada modelo de EAD. O Ambiente Virtual de Aprendizagem - AVA é o resultado de uma plataforma pensada e organizada para um curso.

Sabe-se que, na atualidade, além de uma plataforma estruturada há necessidade de utilizar outros recursos e aplicativos que comumente são utilizados pelos alunos e que podem ser adaptados para o processo de aprendizagem. O WhatsApp e o Skype são exemplos de ferramentas que facilitam o processo de comunicação e interação.

No decorrer do processo de estruturação da Tutoria Presencial fez-se a opção por utilizar o WhatsApp (aplicativo) como ferramenta de comunicação por dois motivos, o primeiro pelas possibilidades que essa mídia oferece e em segundo lugar pela solicitação dos alunos que fazem uso constante dela.

Trata-se de um aplicativo que viabiliza a troca de mensagens por escrita, por áudio e vídeo, considerando a possibilidade de envio de materiais como imagens e outras extensões. É utilizado nos smartphones, mas também apresenta a facilidade de utilização em notebook e computadores (SOUZA et al, 2016).

Por meio do WhatsApp é possível estabelecer um processo de comunicação e interação quase que simultânea, que ultrapassa as barreiras da distância e lugar, fato que, de um 
lado gera a necessidade de um atendimento espontâneo, por se tratar de uma interação síncrona e do outro possibilita a flexibilidade de horário e lugar (MATTAR, 2012).

Outra forma de contato com alunos, que é uma ferramenta gratuita é o Skype, um software da Microsoft (2018), que permite contato por vídeo, voz, mensagem e SMS. Trata-se de uma ferramenta que permite conversas com pequenos grupos e ultrapassa as distâncias. Pode ainda ser utilizado no celular e no computador.

De acordo com Mattar (2012) o Skype tem sido utilizado na EAD por ser uma ferramenta de comunicação gratuita e que já há uma comunidade aberta chamada de Skype in the classroom, que pode ajudar docentes na utilização da ferramenta para o processo de aprendizagem.

Sabe-se que o aluno de curso EAD tem um perfil variado e pertence a diversos contextos sociais e culturais. Este fato exige que a instituição que oferece curso EAD esteja preparada para atender o desafio de uma educação para um público diverso, considerando um processo de melhoria contínua para manter a qualidade (POSSATO et al, 2017).

Ressalta-se que o aluno de curso EAD faz parte de uma nova demanda discente que busca o aprendizado como corresponsável pelo próprio processo de aprendizagem. Esse aluno está no centro do processo educacional e a qualidade do curso está entrelaçada na interação entre aluno e professor, mediada pelas tecnologias (BRASIL, 2002).

Esse aluno precisa ser flexível e estar aberto a novas experiências (PALLOFF; PRATT, 2017). Isso inclui novas experiências tecnológicas devido ao avanço que se vê na sociedade e nova forma de estudar, com outro olhar para o conhecimento e novas habilidades para questões tecnológicas. A EAD é uma nova realidade que valoriza a autonomia do alunado, que por vez podem ser adquiridas com disciplina (BASEGGIO; MUNIZ, 2009).

Se de um lado há o aluno que precisa assumir uma postura diferenciada na EAD, de outro está o Tutor. Mattar (2012) já afirmou que o termo tutor é uma nomenclatura que deveria ser superada, na verdade é o professor. Mas, independente do nome a função é de mediador do processo de aprendizagem, um termo bastante atual na docência. $O$ Tutor é considerado ainda como uma ponte para a habilidade da construção do conhecimento (SOUZA, 2004). 
O Artigo 8o da Resolução n. 1/2016 apresenta o tutor como profissional que presta suporte às atividades do curso, bem como faz a mediação junto aos alunos (BRASIL, 2016). Trata-se de um profissional que tem vários papéis: o social, o pedagógico, o intelectual e o tecnológico (MATTAR, 2012).

Além disso, esse profissional deve sem comprometido, empático, afetivo, comunicativo, desenvolver uma escuta atenta e respeitosa, ser tolerante (SOUZA, 2004). Esse profissional precisa ter uma relação efetiva com o aluno, como fator essencial para a aprendizagem e a qualidade no processo educacional (BENTO et al, 2017).

A partir dessas discussões é relevante considerar a função da Tutoria na EAD, como fator de aproximação com o aluno por meio da interação e da comunicação estabelecida e que deve contribuir para a aprendizagem e aproveitamento do curso, no intuito de possibilitar a formação de um bom profissional.

\section{3 - Procedimentos Metodológicos e Análise}

Tem-se na elaboração de uma pesquisa a necessidade de traçar seu caminho metodológico. Dessa forma esta pesquisa é descritiva com abordagem qualitativa e apresenta relato do setor e das funções da Tutoria Presencial, que foi estruturada numa Instituição Universitária.

Como delimitação é apresentada uma Instituição de Ensino Superior, com mais de quatro décadas de experiência e tradição, a EAD-UNITAU, situada na RMVPLN, e que desde 2009 tem autorização para oferecer cursos na modalidade EAD e os discentes dos 28 cursos da modalidade.

A recente trajetória implica no desvelar de um novo cenário educacional pela instituição, que oferece cursos de Licenciaturas, de $2^{2}$ Licenciaturas, Bacharelado e Tecnólogos. Apresenta-se, a seguir, uma caracterização da Tutoria Presencial estruturada e implantada em 2018.

\section{1 - Caracterização da Tutoria Presencial}

A UNITAU iniciou a primeira turma de EAD em 2011 e à época a Tutoria era realizada 
pelo Docente de Apoio de cada curso, considerando a quantidade inicial de alunos. Esse profissional tinha como função produzir as salas web para a plataforma educacional, as avaliações do curso, a aula presencial de cada disciplina e a tutoria na plataforma.

À medida que o número de alunos foi aumentando houve necessidade de uma nova estruturação do setor de Tutoria. No ano de 2015 foi elaborado um modelo de Tutoria Eletrônica para atendimento exclusivo via plataforma educacional, que foi implantada em 2016, após realização de concurso público por se tratar de uma instituição pública municipal, de economia mista.

O modelo de Tutoria Eletrônica foi apresentado no 22ำ CIAED, intitulado "Tutoria Eletrônica: uma perspectiva de mediação pedagógica e interação" (ALMEIDA et al, 2016). Nesse trabalho foi esmiuçada a função da Tutoria Eletrônica, que tem um trabalho voltado exclusivamente para atendimento do alunado no Ambiente Virtual de Aprendizagem - AVA.

Esse atendimento tem como premissa o processo de mediação e interação com os alunos, por meio das ferramentas disponibilizadas pelo AVA, que neste caso é hospedado no Moodle. As ferramentas são: mensagem individual e grupal, chat, fórum e feedback das correções. Priorizam-se as orientações dos conteúdos pedagógicos e específicos dos cursos. O contato é realizado somente pela plataforma (AVA) e não há outro instrumento midiático de contato.

É neste ponto que se observou a necessidade de ampliar a forma de atendimento aos alunos, pela Tutoria Presencial, inclusive utilizando o aporte de mídias e ferramentas de comunicação, além de plantões presenciais. Considera-se que a interação é fator importante na aprendizagem e um curso EAD precisa estar sustentando por um processo de comunicação que permita resolução rápida de variados conteúdos e aspectos (BRASIL, 2002).

No entanto, antes de esmiuçar a Tutoria Presencial é necessário falar do profissional que foi pensado para assumir esta função. Para desempenhar a função de Tutor Presencial optou-se pela realocação dos Docentes de Apoio para plantões no polo de apoio presencial, na matriz da instituição. Esses docentes, já conhecedores dos seus respectivos cursos foram formados para atendimento personalizado aos alunos, considerando orientações diversas para os atendimentos que serão apresentados adiante. 


\section{2 - Atendimento aos Alunos}

Observou-se no decorrer do tempo que os alunos, além de uma plataforma estruturada precisavam de atendimento para variados tipos de informações. Essas informações abordam as seguintes categorias:

- Acadêmicas: financeiro; plano de estudos; provas; secretaria;

- Curriculares: atividades complementares e atividades teórico-práticas; ENADE, estágio; nivelamento e oficinas;

- Pedagógicas: notas; orientações pedagógicas; provas e correções; sala web AVA; trabalho de conclusão de curso, tutoria eletrônica;

Com base nas necessidades identificadas ao longo do tempo e por levantamento interno é que se estruturou a Tutoria Presencial para dar assistência aos alunos. Para tanto foi disponibilizado também algumas ferramentas de comunicação para viabilizar o processo, como: WhatsApp, Skype, Telefone fixo e móvel, canal de Fale Conosco.

Para a função de Tutoria Presencial há necessidade de plantões semanais de oito horas. Esses plantões são estruturados conforme a necessidade do curso e disponibilidade dos Docentes e estão concentrados no período da tarde e noite, de segunda a sexta e pela manhã aos sábados.

Dentre as funções, o Tutor Presencial nos plantões é necessário: estabelecer contato com os alunos; verificar as demandas (email, sistema, plataforma, whatsapp, skype, telefone); encaminhar os casos; registrar os atendimentos; aplicar provas; corrigir provas; lançar notas no sistema acadêmico; orientar Trabalho de Conclusão de Curso; fazer atendimento presencial; participar das formações e reuniões mensais;

Quando o Tutor recebe do aluno algum questionamento ou necessidade de informação deve encaminhar o questionamento ao setor responsável e acompanhar a resolução do caso e dar feedback ao aluno. Quando o profissional detém a resposta deve dar seguimento imediato ao aluno e encerrar o atendimento com o registro do mesmo num sistema acadêmico interno da Instituição.

Todo atendimento ou encaminhamento é registrado neste sistema interno, fato que possibilita acompanhar o caso, sobretudo pela supervisão e coordenação. O mais importante neste contexto é a resposta ao questionamento do aluno e ao mesmo tempo o estabelecimento de comunicação e interação. 
De outra forma os registros permitem ainda quantificar os atendimentos e mapear os processos que precisam de melhoria no fluxo e na comunicação. Esta (re)estruturação, além de possibilitar que o aluno tenha facilidade de contato permite respostas mais rápidas e efetivas e ainda contribui para o processo de melhoria contínua da $E A D$ considerando que se trata de uma modalidade em constante movimento.

\section{4 - Algumas Considerações}

A EAD é uma modalidade em constante movimento e cabe às instituições que oferecem esse tipo de educação acompanhar a evolução para conseguir atender às expectativas e necessidades dos alunos e para manter a qualidade dos cursos oferecidos. $\mathrm{Na}$ estruturação dos cursos é preciso adotar ferramentas que possibilitem comunicação e interação com os alunos, a partir de aplicativos e softwares que estão próximos da realidade dos alunos.

Nesse sentido, este relato teve por intenção apresentar um modelo de Tutoria Presencial estruturado na EAD UNITAU para estabelecer uma rotina de atendimento aos alunos por meio de plantões presenciais no polo matriz da EAD. Essa Tutoria é realizada por docentes que já atuavam nos cursos e passaram a se inteirar de questões cotidianas que necessitavam de resposta mais rápida e que versavam sobre questões acadêmicas, curriculares e pedagógicas.

Nos primeiros três meses de Tutoria Presencial houve necessidade de divulgação dos plantões, para que os alunos tomassem conhecimento da ajuda que poderiam ter dos docentes dos cursos. De início a procura foi pequena e aumentando a cada mês. A ferramenta mais utilizada foi o WhatsApp, seguida do canal Fale Conosco.

Por fim foi possível obter como resultado o fato da procura dos alunos ter aumentado à medida que os plantões foram divulgados, sendo a procura pelo plantão uma forma de buscar respostas de forma mais rápida e efetiva.

\section{Referências}

ALMEIDA, Antônia Lucineire. MONTEIRO, Patrícia Ortiz. BUSSOLOTTI, Juliana Marcondes. Tutoria Eletrônica: uma perspectiva de mediação pedagógica e interação. 
22ํㅡㄹ Congresso Internacional ABED de Educação a Distância - CIAED. Anais... Águas de Lindóia, 2016.2 Disponível em: http://www.abed.org.br/congresso2016/trabalhos/135.pdf. Acesso em: 02/04/2018.

ALVES, Lynn. BARROS, Daniela. OKADA, Alexandra (org.). Moodle Estratégias Pedagógicas e Estudos de Caso. Salvador: EDUNEB, 2009. Disponível em: http://www.moodle.ufba.br/file.php/1/Moodle_1911_web.pdf. Acesso em: 02/05/2018.

BASEGGIO, Karina Roberta. MUNIZ, Eray Proença. Autonomia do Aluno de EAD no Processo de Ensino e Aprendizagem. Revista Tecnologia e Sociedade. v. 5, n. 8, 2009. Disponível em: https://periodicos.utfpr.edu.br/rts/article/view/2531/1646. Acesso em: $23 / 04 / 2018$.

BENTO, Luiz. NASCIMENTO, Milena de Sousa. GRENHA, Viviane. MACEDO, Margarete Valverde. A Concepção de Tutores a Distância sobre Interatividade e a formação em EAD: um estudo de caso. Revista Brasileira de Aprendizagem Aberta e a Distância. 2017.2 Disponível em: http://seer.abed.net.br/edicoes/2017/ABED2017-2.pdf. Acesso em: 29/03/2018.

BRASIL, Ministério da Educação. Portaria n. 335/2002. Relatório Final da Comissão Assessora para Educação Superior a Distância. Brasília, DF: MEC, 2002. Disponível em: http://portal.mec.gov.br/sesu/arquivos/pdf/EAD.pdf. Acesso em: 14/04/2018.

MATTAR, João. Tutoria e Interação em Educação a Distância. São Paulo: Cengage Learning, 2012.

MICROSOFTC. Skype. 2018. Disponível em: https://www.skype.com/pt-br/ Acesso em 02/05/2018.

MASETTO, Marcos Tarcísio. Mediação Pedagógica e o Uso da Tecnologia. In: MORAN, José Manuel. MASETTO, Marcos Tarcísio. BEHRENS, Marilda Aparecida. Novas Tecnologias e Mediação Pedagógica. Campinas, SP: Papirus, 2000.

PALLOF, Rena M. PRATT, Keith. O Aluno Virtual: um guia para trabalhar com estudantes online. Trad. Vinícius Figueira. Ebook. Porto Alegre: Artmed, 2007.

POSSATO, Álvaro. ALMEIDA, Antônia Lucineire. PIRES, Rosana Giovani. MONTEIRO, Patrícia Ortiz. As Representações Sociais de Alunos sobre a Plataforma Educacional de Cursos EAD. XIII Congresso Nacional de Educação - EDUCERE. Anais... Curitiba, 
2017. Disponível em: http://educere.bruc.com.br/arquivo/pdf2017/26366_13288.pdf. Acesso em: 30/03/2018.

SILVA, Robson Santos. Gestão de EAD: educação a distância na era digital. São Paulo: Novatec, 2013.

SOUZA, Lídia Ramos Aleixo. FREITAS, Cesar Bento. SANTOS, Juçara Maria Montenegro Simonsen. WhatsApp - Inimigo ou Aliado na Educação: um estudo de caso sob a ótica dos discentes. 22을 Congresso Internacional ABED de Educação a Distância - CIAED. Anais... Águas de Lindóia, SP. 2016. Disponível em: http://www.abed.org.br/congresso2016/trabalhos/113.pdf. Acesso em: 24/04/2018.

SOUZA, Matias Gonzalez. A Arte da Sedução Pedagógica na Tutoria em Educação a Distância. 10 Congresso Internacional ABED de Educação a Distância - CIAED. Anais... Porto $2004 . \quad$ Disponível em: http://www.abed.org.br/congresso2004/por/htm/001-TC-A1.htm. Acesso em: 14/04/2018. 